\section{Science for the people}

Scott Schneider, Edward Loechler, Jonathan King and Jonathan Beckwith of Science for the People reply to Alvin Weinberg's article 'Science for the people, or by the people?' (3 August, page 410).

Alvin Weinberg has criticised the position of Science for the People on United States cancer policy, and attacked the general idea of public participation in choosing the scientific routes to social goals. He has also commented on the actions of Science for the People in the anti-war movement.

Widespread public participation was crucial in stopping US military intervention in Vietnam. We believe that Science for the People's efforts to raise consciousness of the misuses of science and technology - such as chemical defoliants, the electronic battlefield and counterinsurgency research-against the Vietnamese helped to end that war.

Weinberg does not accurately represent our position on cancer research, which has appeared in Science for the People magazine (vol VII, September 1975; vol VIII, July 1976). Although the war on cancer channelled billions of dollars into needed biochemical research, the major thrust was limited to tumour biology, tumour virology, and cancer therapy. During the first five years, less than $5 \%$ of the research budget was spent on identifying the agents causing cancer. This was in spite of longstanding epidemiological evidence that most human cancer was environmentally caused, and, therefore, preventable (see S. Epstein, Environmental Determinants of Human Cancer, Cancer Res. 34, $2425-2435,1974$, and references therein). These environmental agents include such chemical carcinogens as benzidine, vinyl chloride, and other occupational hazards such as asbestos and radiation. For example, New Jersey, the most heavily industrialised state, had the highest cancer incidence in the US for the period 1950 to 1969 . The bladder cancer rate in Salem County, NJ, where $25 \%$ of the workforce is employed in the chemical industry, is highest in the country. In addition to the epidemiological evidence, there was a well formulated biological model for the role that chemicals may play in cancer, somatic mutation (Ryser, New Eng. J. Med. 285, 721-734, 1971, and references therein); yet the National Cancer Institute (NCI) pursued a research policy concentrating on curing the affected individual to the neglect of decreasing the incidence of the disease.

Although we approve of increased research in the area of nutrition in the cancer programme, we are suspect of Senator Dole's emphasis on the role of diet per se. General dietary factors are probably important in the aetiology of cancer, for example the effects of high fat intake. However, a major focus of such research should be on the many carcinogenic food additives which bear little relation to nutritional needs and serve mainly to improve marketability. Other potential dietary carcinogens, including residual pesticides or byproducts of the preparation process, should also be studied. While we support research in these areas, we should not allow a shift in emphasis from cures for cancer to nutritional studies to deflect attention from the other major environmental sources of cancer.

We believe that factors other than the internal state of scientific knowledge determined the systematic underfunding of research focusing on environmental and occupational causes of cancer. For example, in 1952, William Hueper, chief of NCI's Environmental Cancer Section attempted to study the incidence of cancer among chromate workers. The chromate industry management complained that the project was detrimental to their interests and the surgeon general halted the project (L. Agran, The Cancer Connection, Houghton-Mifflin, Boston, 1977). Hueper was prevented from doing any occupational studies and was later dismissed for his persistent efforts in that direction. In 1973, Nixon's Science Advisory Committee issued a major report, Chemicals and Health, which supported a continuation of the status quo in cancer research priorities. Considering the composition of the committee, which included six representatives of large corporations (Bell, Dupont, IBM, Texas Instruments, Digital Equipment and Turner Construction) and none from labour, environmental, or public interest groups, this conclusion is not surprising. Furthermore, the continued refusal of corporations to allow researchers access to workers' health records has severely inhibited epidemiological studies. At present, the American Industrial Health Council (representing corporate interests) is waging a campaign against the efforts of the Occupational Safety and Health Administration (OSHA) to pass generic standards protecting US workers from occupational exposure to known carcinogens (Chemical and Engineering News, 30 January, 1978, pp30-35).

A focus on environmental and occupational carcinogens leads to social policies requiring clean-up of the workplace and elimination of pollution. This generally entails increased production costs and, as a result, reduced profits. In contrast, research into cures for cancer or the viral aetiology of cancer does not threaten corporate interests. It seems likely that this is why corporations and their representatives in government have focused research efforts away from environmental causes of cancer, including chemicals.

In the last few years NCI policy has begun to change. A major factor leading to this change was the struggle to have OSHA pass standards limiting occupational exposure to asbestos, vinyl chloride and other carcinogens. The initially management-oriented OSHA administration was forced to set standards through pressure from trade unions such as the Oil, Chemical and Atomic Workers, public interest groups, notably the Health Research Group, and progressive journalists such as Paul Brodeur. Through these efforts, information about carcinogens became publicly available, and the important scientific contributions of researchers such as Ames, the Millers, Selikoff and Saffioti came to the fore. This public pressure led OSHA, under new leadership, to take up the fight within government to protect its constituency, workers, from cancer. Subsequently, continued efforts by trade unions, environmental and other public interest groups, often acting through their elected representatives (see Leonard Woodcock, United Auto Workers, testimony before the Subcommittee on Health and Scientific Research of the US Congress, April, 1977), forced a change in cancer research policy. Without their contribution, research on the mechanism of carcinogenesis, still in its infancy, would not have developed to the extent that it has.

Science for the People believes that the development of scientific knowledge should benefit all sectors of society and that this requires informed public participation. However, in our society, where there are major inequities in the distribution of resources, the forces which generally predominate in the setting of scientific priorities are those with the greatest wealth and influence. What the history of cancer research policy in the US demonstrates is that the means by which scientists set out to achieve a society's goal can be just as heavily politically influenced as the goals themselves. In this case, struggles between corporate interests, on the one hand, and workers and their supporters, on the other, caused shifts in priorities. In fact, the cancer issue also shows that it is only through the pressure from an informed public that certain types of research which were closed off from 'freedom of inquiry' became open. To suggest then, as Weinberg does, that the public has no role in determining the lines of approach which scientists take is to ignore the forces which already shape scientific research. 